\title{
Non-Operative Management of Acute Appendicitis - Evidence versus Practice in Eastern Health, Victoria, Australia
}

\author{
Allan $\mathrm{Z}^{*}$ and Al-Habbal Y \\ Department of General Surgery, Box Hill Hospital, Melbourne, Victoria, Australia \\ ${ }^{*}$ Corresponding author: Allan Z, 230 Burwood HWY, Burwood East, VIC, 3151, Fax: +61397646285, Tel: \\ +61420853245, E-mail: zZx_1989@hotmail.com
}

Citation: Allan Z, Al-Habbal Y (2018) Non-Operative Management of Acute Appendicitis - Evidence versus Practice in Eastern Health, Victoria, Australia. J Surg Oper Care 3(2): 205. doi: 10.15744/24557617.3.205

Received Date: July 12,2018 Accepted Date: August 1, 2018 Published Date: August 3, 2018

\begin{abstract}
Introduction: There has been an increasing body of literature on conservative management of acute appendicitis recently. The aim of this study was to evaluate the current practice of non-operative management of acute appendicitis in Eastern Health, a Melbourne metropolitan health network

Method: A retrospective observational study was conducted for all patients managed conservatively for acute appendicitis at Eastern Health between July 2011 to December 2016

Results: There were 54 patients managed conservatively and 1516 patients managed operatively for acute appendicitis. Within the conservative treatment cohort, simple appendicitis was found in 19 patients and complicated appendicitis was found in 35 patients. Follow up period was between 6 and 24 months. The recurrence rate was $20.4 \%$ (11 patients). Interval appendicectomy rate was $25.9 \%$ (14 patients). Interval colonoscopy rate was $37 \%$ (20 patients)

Conclusion: Appendicectomy is currently the mainstay treatment of acute appendicitis in our health network. Nevertheless, conservative management is a safe and valid alternative. Our recurrence rate for appendicitis treated conservatively is comparable to the literature. Despite ample evidence against interval appendicectomy, it is still being offered to patients. Interval appendicectomy and interval colonoscopy should not be a routine practice and should be selectively offered to patients

Keywords: Appendicectomy; Appendicitis; Conservative management; Colonoscopy

List of abbreviations:

NHMRC:National Health and Medical Research Council; CT:Computed Tomography; US:Ultrasonography; IV:Intravenous; WBC:White Blood Cells; CRP:C Reactive Protein
\end{abstract}

\section{Introduction}

Acute appendicitis is the most common cause of acute abdominal pain leading to hospital admission and surgery. About $20 \%$ of the cases are complicated with perforation, peritonitis or collection while majority is uncomplicated [1]. The first appendicectomy for acute appendicitis was performed by McBurney in 1889 [2]. In patients with complicated appendicitis, the preferred management is largely conservative as there is strong evidence to suggest operative management during acute admission leads to higher rates of morbidity and mortality [3-6]. Appendicectomy has been the preferred option in treatment of acute uncomplicated appendicitis since the 19th century. It is well tolerated by majority of the patients with a high cure rate however complications including serious intra-abdominal organ injuries still exist $[7,8]$. The emergence, and increased use of laparoscopy was associated increased numbers of surgical intervention with high negative appendicectomy rates and unnecessary surgery related complications [7-9]. In the past two decades, there has been an increasing body of literature evaluating the validity of antibiotics treatment alone in managing acute uncomplicated appendicitis and results are promising [10-18]. With this shifting trend in management of acute appendicitis we aim to review the performance in management of acute appendicitis in our health network in the past five years, focusing on the cohort of patients managed conservatively, the management decisions and follow up results.

\section{Methods}

A retrospective observational study was conducted within Eastern Health hospital network which is a tertiary referral centre 
in Melbourne, Australia. The study was approved by the Office of Research and Ethics at Eastern Health (Reference QA302017), which is accredited by the National Health and Medical Research Council (NHMRC) of Australia. All patients presented to Eastern health network hospitals with the diagnosis of Appendicitis or related conditions between July 2011 to December 2016 were isolated by the Health Information and Records Department using the International Classification of Diseases, tenth revision, Clinical Modification (ICD-10-CM). Those diagnostic codes included K35.2, acute appendicitis with generalised peritonitis; K35.3, acute appendicitis with localized peritonitis; K35.8, acute appendicitis, other and unspecified; K36, other appendicitis; and K37, unspecified appendicitis. From this cohort, patients who were managed conservatively (did not receive operative appendicectomy) within the same admission were selected and further evaluated. Patients were included in this study if they had clear radiological diagnosis of acute appendicitis and were treated conservatively. Patients who were transferred to other hospitals, and those who were admitted for observation of abdominal pain without any imaging confirmed diagnosis of appendicitis, were excluded from this study. Information were gathered from Electronic Medical Records. Diagnostic imaging modality were classified into Computed Tomography (CT) scans, Ultrasonography (US) scans and other. Diagnoses were further classified into simple appendicitis, and complex appendicitis (perforated appendicitis, appendiceal collection or abscess, and appendiceal phlegmon). Inpatient management determined the use of antibiotics and whether patients required radiologically guided intervention. Patients were followed up to 24 months post discharge (follow up period ranged between 6 to 24 months with median follow up period of 24 months). Information on outpatient colonoscopy, interval appendicectomy and recurrent appendicitis episodes were collected.

\section{Results}

There were 1986 patients admitted with the diagnosis of possible appendicitis or related conditions during the study period. There were 1516 patients who required operative management and 470 patients with no operative intervention recorded. Within the 470 patients, majority did not have imaging confirmed appendicitis, some were transferred to the other hospitals early on during their admission and others had other intra-abdominal pathology confirmed instead of appendicitis. A total of 54 patients satisfied the inclusion criteria and were selected for this study (0.04\%) (Figure 1). There were 28 female and 26 male patients with a median age of 59.5 years (range 8 - 94). Forty-six patients (85.2\%) had CT scan confirmed diagnoses, 4 patients $(7.4 \%)$ had US scans only and 4 patients (7.4\%) required both CT and US scans. Nineteen patients (35.2\%) had imaging confirmed simple appendicitis. Four patients were deemed unfit for general anaesthesia with multiple comorbidities; one patient declined surgical treatment; three patients had imaging findings suspicious for other pathology (in addition to acute appendicitis) and eleven patients were clinically well and improved rapidly with intravenous antibiotics (Table 1). Thirty-five patients (64.8\%) had imaging confirmed complicated appendicitis (ruptured appendicitis, appendiceal abscess and phlegmon). All 54 patients received inpatient intravenous (IV) broad-spectrum antibiotics and 10 patients (18.5\%) required radiological guided percutaneous drainage of
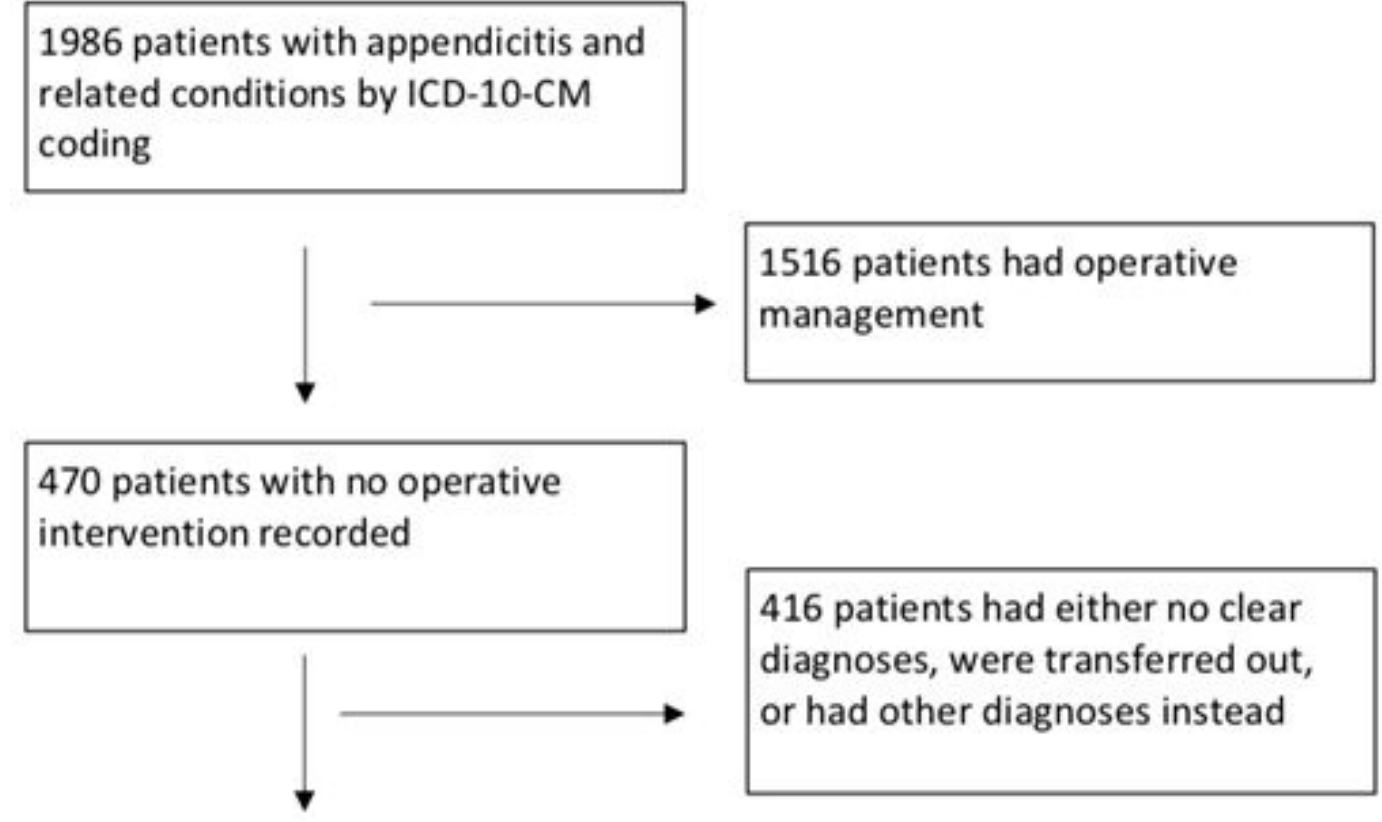

\section{4 patients satisfied inclusion criteria}

Figure 1: Flowchart of inclusions and exclusions 


\begin{tabular}{|c|c|}
\hline Reasons & Numbers \\
\hline $\begin{array}{c}\text { Unfit (Medical co-morbidities) } \\
\text { Imaging finding of other pathology (In } \\
\text { addition to appendicitis) }\end{array}$ & 4 \\
\hline Declined surgery & 1 \\
\hline $\begin{array}{c}\text { Clinically well and rapidly improved on } \\
\text { antibiotics }\end{array}$ & 11 \\
\hline Total & 19 \\
\hline
\end{tabular}

Table 1: Reasons for conservative management of simple appendicitis

appendiceal collection. During follow up, 20 patients (37\%) received outpatient colonoscopy (Table 2); 4 of which had simple appendicitis and 16 had complicated appendicitis (Figure 2). Eighteen patients had normal follow-up colonoscopy. One patient had colitis where there was a known history of Ulcerative colitis. One patient's colonoscopy report could not be retrieved (Figure 3). Eleven patients (20.4\%) had recurrent appendicitis episodes over the follow up period (Table 2); three had simple appendicitis initially and eight had complicated appendicitis. Four of the eleven patients were managed conservatively again and seven required operative management (4 laparoscopic and 3 open procedures). In total, 21 patients (38.9\%) received appendicectomy in the follow up period, 14 patients underwent interval appendicectomy and 7 required emergency appendicectomy during their second admission of acute appendicitis (Figure 4). Of the 14 patients (25.9\%) undergone elective interval appendicectomy, surgery was recommended to 9 asymptomatic patients by their treating surgeons, three patients were offered interval appendicectomy post conservative management of their second episode of appendicitis and 2 patients had interval appendicectomy due to ongoing abdominal pain (Figure 5).

\begin{tabular}{|c|c|c|}
\hline & Yes & No \\
\hline Colonoscopy & $20(37 \%)$ & $34(63 \%)$ \\
\hline Interval appendicectomy & $14(25.9 \%)$ & $40(74.1 \%)$ \\
\hline Recurrent episode & $11(20.4 \%)$ & $43(79.6 \%)$ \\
\hline
\end{tabular}

Table 2: Follow-up post primary admission

\section{Interval colonoscopy}

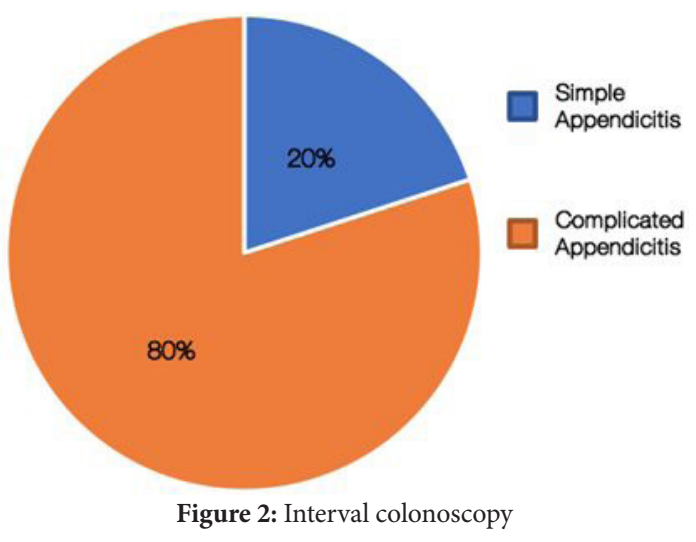

\section{Colonoscopy results}

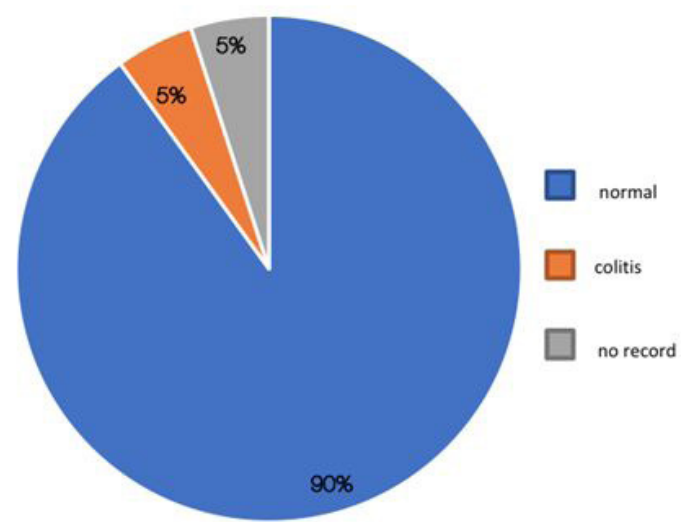

Figure 3: Interval colonoscopy results 


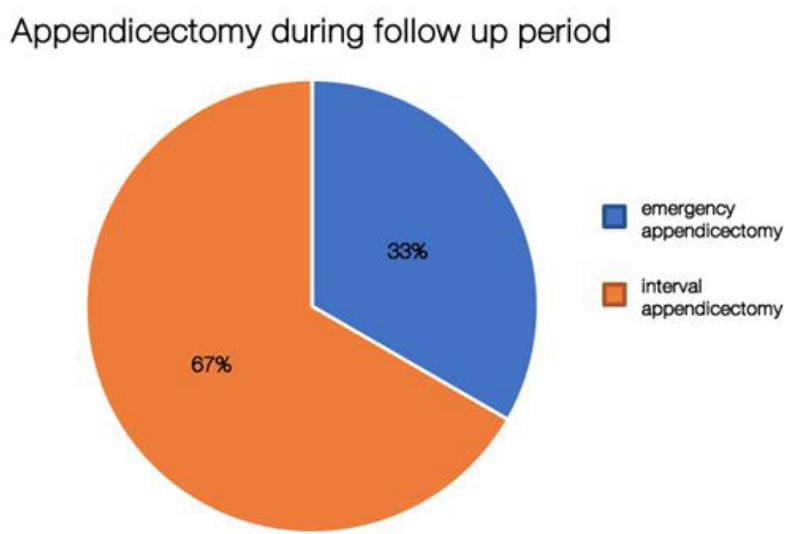

Figure 4: Total appendicectomy during follow up period

\section{Reasons for interval appendicectomy}

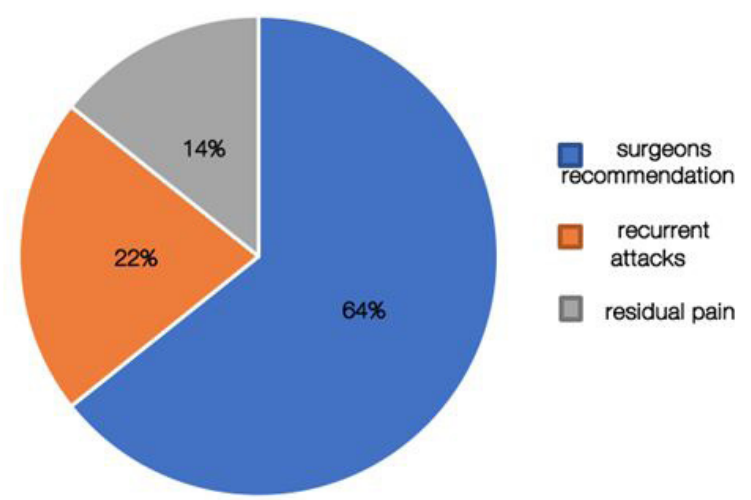

Figure 5: Reasons for interval appendicectomy

\section{Discussion}

Not surprisingly, appendicectomy is currently the mainstay treatment of acute appendicitis in our health network reflected by our study numbers (54 conservatively treated patients versus 1516 surgically treated patients), whereas conservative treatment was only occasionally adopted. The concept of conservative management of acute appendicitis over appendicectomy has been proposed for over two decades now. There have been several randomized controlled trials and multiple systematic reviews looking at safety and efficacy of antibiotics alone versus appendicectomy in treating acute uncomplicated appendicitis [10-16,19].

Several trials supported conservative management of uncomplicated appendicitis. Styrud et al., Hansson et al. and Eriksson et al. assessed patients with clinical appendicitis treated conservatively with antibiotics versus patients treated by appendicectomy and concluded that antibiotic treatment alone is as effective as appendicectomy [10-12]. Different parameters are used for assessment. Styrud and colleagues compared complication rate in appendicectomy group to recurrence rate in antibiotics group and found them to be the same [11]. Hansson and colleagues utilized similar criteria; they defined efficacy in antibiotic group as definite improvement without the need for surgery within a median follow up of 1 year; efficacy in appendicectomy group was confirmed appendicitis at operation or another appropriate surgical indication for operation [12]. They found comparable efficacy between the two groups [12]. Eriksson et al compared pain score, white blood cell (WBC) and C-reactive protein (CRP) levels and found that patients treated with antibiotics had a significantly lower pain level and faster decrease in WBC count when compared to patients treated with appendicectomy [10]. The recurrence rate within 1 year follow up was 35\% in the antibiotic group; and the negative appendicectomy rate was 15\% [10]. Two trials questioned the efficacy of conservative management of uncomplicated appendicitis. Salminen et al. and Vons et al. both used non-inferiority criteria and found they were unable to demonstrate non-inferiority of antibiotics treatment relative to surgery $[15,16]$. Salminen et al. defined successful treatment of antibiotics as discharge from hospital without needing surgery and no recurrent appendicitis within 1 year of follow-up; and defined successful surgical treatment as completion of an appendicectomy [16]. Despite the reported 25\% difference in efficacy between the two groups, antibiotics group achieved $94.2 \%$ successful discharge rate during the initial inpatient stay [16]. Vons and colleagues defined primary end point as occurrence of post-intervention peritonitis within 30 days of treatment initiation and found that this occurs significantly more frequent in the antibiotics treatment group than in the appendicectomy group (8\% versus $2 \%$ ) [15]. Complicated appendicitis on the other hand is defined as acute appendicitis with the presence of abscess, localized perforation, or inflammatory mass consisting of inflamed appendix and adjacent viscera [6]. Their management is usually more controversial. Clinically those patients present very similar to patients with acute uncomplicated appendicitis, however on examination there 
may be a palpable mass in the right iliac fossa [5,6]. General consensus of first-line treatment is conservative antibiotic treatment with or without the aid of radiological guided drainage of abscess $[3,5,6]$. Differently to uncomplicated appendicitis, conservative treatment is preferred to avoid possible spread of localized infection, injury to surrounding viscera and overall high complication rate that surgery brings [6]. One study shows immediate surgery in patients with phlegmon formation is associated with over a three-fold increase in morbidity compared with conservative management [4]. A meta-analysis done by Simillis and colleagues showed significantly increased rate of overall complications, re-operation, wound infection, ileus or bowel obstruction and abdominal or pelvic abscess formation in patients undergoing immediate operation versus conservative management [5]. Only a small cohort of patients (19 patients) with simple appendicitis received non-operative management during the study period in our health network. Majority of the conservatively managed patients had complex appendicitis (35 patients). When further examined, more than half of these 19 patients were clinically well with minimal tenderness, the rest were either too unwell for anaesthesia or had other imaging findings complicating the diagnosis of simple appendicitis (Table 2). It is clear that operative management is preferred in managing simple appendicitis in our health network. One reason could be the implementation of the Acute General Surgical Units at two of our hospitals, where acute appendicitis can be readily managed operatively. Another reason could be the lack of locally based trials and data. We believe our results represent the current practice in Melbourne, Australia.

\section{Interval Appendicectomy}

Interval appendicectomy is defined as appendicectomy after successful conservative management of acute appendicitis to prevent future recurrent episodes. Whether this should be carried out as a routine approach or not, remains controversial. In our study, 14 patients (24.9\% of conservative group) had undergone an elective interval appendicectomy during the follow up period, $64 \%$ (9 patients) of which did not have any residual symptoms or signs of recurrent episodes and only $36 \%$ (5 patients) had recurrent episodes or residual symptoms. There is no consensus in our centre on who should receive interval appendicectomy and who should not. Studies have questioned the necessity of interval appendicectomy as the complication rate can be as high as $23 \%$ and the recurrence rate is low ranging from 5-15\% in a follow up period between 6 to 48 months [14,20-22]. Some argue that in complicated appendicitis, there is a potential risk of underlying malignancy or other pathology, i.e., Crohn's disease, being missed and interval appendicectomy and histopathology testing can provide more diagnostic and treatment value [4,23]. Others have offered the alternative CT scans and colonoscopy in suspected cohort for detecting that rare pathology [21]. Current evidence from systematic reviews is against routine interval appendicectomy even in complicated appendicitis and some studies suggest that recurrences may be observed and managed conservatively again [14,21,22,24, 25].

\section{Predictors of Recurrent Episodes}

Recurrent episodes of appendicitis post conservative management warrant attention and treatment. It would be very helpful if predictors of recurrence can be identified so that such population can be offered interval appendicectomy or appropriate follow up. From our study, 20.4\% (11 patients) had recurrent episode within the follow-up year, comparable to the reported literature figure of 3 to $25 \%$ [3,6,10-12,14]. Majority (8 patients) of those patients had complicated appendicitis during their initial presentation. One case-control study of paediatric population found that persistent symptoms after resolution of the appendicular inflammatory mass and resolution time of more than 6 days strongly correlates with recurrence and those patients should be offered interval appendicectomy [26]. They also established a significant correlation between US positive appendicolith and recurrence [26]. Also in paediatric population, Koike and colleagues retrospectively examined several factors and identified using multivariate analysis that intraluminal appendiceal fluid on imagine (CT or US scans) is a significant independent predictor of recurrent appendicitis [27]. Another study analysed radiological findings on CT scans and found that the presence of calcified appendicolith strongly relates to recurrence of appendicitis [28].

\section{Interval Colonoscopy}

Our study demonstrated a 37\% (20 patients) interval colonoscopy rate in the conservative treatment cohort. Majority of those patients (16 patients) had complicated appendicitis. Apart from one patient who had colitis on colonoscopy with the background of Ulcerative colitis, rest of the colonoscopies did not detect other disease process. Apparently, there is also no consensus in our health system on who should receive colonoscopy and who should not. There is an up to $12 \%$ chance that complicated appendicitis, especially with the presence of an inflammatory mass, could be the initial presentation of other disease processes [29]. These include ruptured caecal diverticulitis, terminal ileitis, mesenteric tumours, carcinoid of the appendix, mucocele of the appendix and caecal cancer $[14,23,30]$. Carcinoid is the most common tumour of the appendix with an incidence of $0.3 \%-0.7 \%$ [31]. There is about a 1-4\% association of appendiceal mass with caecal or ascending colon cancer [29, 32]. Suspicion should be raised in the at-risk group of age more than 40 years, presence of anaemia, recurrent pain in the right iliac fossa, histologically normal appendix post appendicectomy $[14,32]$. Lai and colleagues strongly advocates an interval colonoscopy in patients presenting with appendiceal mass that have been managed conservatively [29]. This study has some limitations. Being retrospective, it is subjected to selection bias. Though this was minimized by following strict selection criteria of consecutive patients. Limiting the study to imaging-confirmed appendicitis, meant that patient with clinical appendicitis treated conservatively without imaging were not included in this study. So, the actual number of patients might well be more than the reported number of 54. This was intentional to avoid including patients with non-specific abdominal pain diagnosed clinically as appendicitis. 


\section{Conclusion}

Appendicectomy is still the mainstay treatment of acute appendicitis in our health network currently. Conservative management is usually successful and can be adopted as the first-line treatment of simple appendicitis in specific scenarios, like elderly patients with multiple comorbidities. Conservative management should be the mainstay for complicated appendicitis (mass or abscess). Interval appendicectomy should only be offered to patients with recurrent appendicitis and those with high chance of recurrence based on imaging. Interval colonoscopy should be scheduled for patients with high risk of malignancy and other disease processes, e.g. patients above 40 years of age, and patients with right iliac fossa mass. We believe our study results represent the current practice of management of acute appendicitis in Melbourne, Australia. However, it would be valuable to see and compare results with other health institutions in Australia.

\section{References}

1. Livingston EH, Woodward WA, Sarosi GA, Haley RW (2007) Disconnect between incidence of nonperforated and perforated appendicitis: implications for pathophysiology and management. Ann Surg 245: 886-92.

2. McBurney C (1889) Experiences with early operative interference in cases of disease of the vermiform appendix. N Y Med J 50: 1676-84.

3. Oliak D, Yamini D, Udani VM, Lewis RJ, Arnell T, et al. (2001) Initial nonoperative management for periappendiceal abscess. Dis Colon Rectum 44: 936-41.

4. Andersson RE, Petzold MG (2007) Nonsurgical treatment of appendiceal abscess or phlegmon: a systematic review and meta-analysis. Ann Surg 246: 741-8.

5. Simillis C, Symeonides P, Shorthouse AJ, Tekkis PP (2010) A meta-analysis comparing conservative treatment versus acute appendectomy for complicated appendicitis (abscess or phlegmon). Surgery 147: 818-29.

6. Malik AA, Wani ML, Wani SN, Parray FQ, Nayeem-Ul-Hassan, Irshad I (2012) Evaluating conservative treatment for acute appendicitis with lump formation. J Emerg Trauma Shock 5: 33-5.

7. Konstantinidis KM, Anastasakou KA, Vorias MN, Sambalis GH, Georgiou MK, et al. (2008) A decade of laparoscopic appendectomy: presentation of 1,026 patients with suspected appendicitis treated in a single surgical department. J Laparoendosc Adv Surg Tech A 18: 248-58.

8. Ming PC, Yan TY, Tat LH (2009) Risk factors of postoperative infections in adults with complicated appendicitis. Surg Laparosc Endosc Percutan Tech.19: 244-8.

9. Coursey CA, Nelson RC, Patel MB, Cochran C, Dodd LG, et al. (2010) Making the diagnosis of acute appendicitis: do more preoperative CT scans mean fewer negative appendectomies? A 10-year study. Radiology 254: 460-8.

10. Eriksson S, Granström L (1995) Randomized controlled trial of appendicectomy versus antibiotic therapy for acute appendicitis. Br J Surg 82: 166-9.

11. Styrud J, Eriksson S, Nilsson I, Ahlberg G, Haapaniemi S, et al. (2006) Appendectomy versus antibiotic treatment in acute appendicitis. a prospective multicenter randomized controlled trial. World J Surg 30: 1033-7.

12. Hansson J, Körner U, Khorram-Manesh A, Solberg A, Lundholm K (2009) Randomized clinical trial of antibiotic therapy versus appendicectomy as primary treatment of acute appendicitis in unselected patients. Br J Surg 96: 473-81.

13. Varadhan KK, Humes DJ, Neal KR, Lobo DN (2010) Antibiotic therapy versus appendectomy for acute appendicitis: a meta-analysis. World J Surg 34: 199-209.

14. Sakorafas GH, Mastoraki A, Lappas C, Sampanis D, Danias N, et al. (2011) Conservative treatment of acute appendicitis: heresy or an effective and acceptable alternative to surgery? Eur J Gastroenterol Hepatol. 23: 121-7.

15. Vons C, Barry C, Maitre S, Pautrat K, Leconte M, et al. (2011) Amoxicillin plus clavulanic acid versus appendicectomy for treatment of acute uncomplicated appendicitis: an open-label, non-inferiority, randomised controlled trial. Lancet 377: 1573-9.

16. Salminen P, Paajanen H, Rautio T, Nordström P, Aarnio M, et al. (2015) Antibiotic Therapy vs Appendectomy for Treatment of Uncomplicated Acute Appendicitis: The APPAC Randomized Clinical Trial. JAMA 313: 2340-8.

17. Allievi N, Harbi A, Ceresoli M, Montori G, Poiasina E, et al. (2017) Acute Appendicitis: Still a Surgical Disease? Results from a Propensity Score-Based Outcome Analysis of Conservative Versus Surgical Management from a Prospective Database. World J Surg 41: 2697-705.

18. Charalampopoulos A, Dimopoulos I, Koliakos N, Kopanakis K, And TL (2017) Non-Complicated Acute Appendicitis in Adults Treated Successfully by Conservative Treatment without Recurrences. Chirurgia (Bucur) 112: 25-32.

19. Turhan AN, Kapan S, Kütükçü E, Yiğitbaş H, Hatipoğlu S, et al. (2009) Comparison of operative and non operative management of acute appendicitis. Ulus Travma Acil Cerrahi Derg 15: 459-62.

20. Dixon MR, Haukoos JS, Park IU, Oliak D, Kumar RR, et al. (2003) An assessment of the severity of recurrent appendicitis. Am J Surg 186: 718-22.

21. Sakorafas GH, Sabanis D, Lappas C, Mastoraki A, Papanikolaou J, et al. (2012) Interval routine appendectomy following conservative treatment of acute appendicitis: Is it really needed. World J Gastrointest Surg 4: 83-6.

22. Deakin DE, Ahmed I (2007) Interval appendicectomy after resolution of adult inflammatory appendix mass--is it necessary? Surgeon 5: 45-50.

23. Mazziotti MV, Marley EF, Winthrop AL, Fitzgerald PG, Walton M, et al. (1997) Histopathologic analysis of interval appendectomy specimens: support for the role of interval appendectomy. J Pediatr Surg 32: 806-9.

24. Eriksson S, Styrud J (1998) Interval appendicectomy: a retrospective study. Eur J Surg 164: 771-4.

25. Willemsen PJ, Hoorntje LE, Eddes EH, Ploeg RJ (2002) The need for interval appendectomy after resolution of an appendiceal mass questioned. Dig Surg 19: 216-20.

26. Castelló González M, Bueno Rodríguez JC, Hernández Moore E, Aguilar Atanay D (2014) Predictors of recurrent appendicitis after non-operative management of children with perforated appendicitis presenting with an appendicular inflammatory mass. Arch Dis Child 99: 154-7.

27. Koike Y, Uchida K, Matsushita K, Otake K, Nakazawa M, et al. (2014) Intraluminal appendiceal fluid is a predictive factor for recurrent appendicitis after initial successful non-operative management of uncomplicated appendicitis in pediatric patients. J Pediatr Surg 49: 1116-21.

28. Tsai HM, Shan YS, Lin PW, Lin XZ, Chen CY (2006) Clinical analysis of the predictive factors for recurrent appendicitis after initial nonoperative treatment of perforated appendicitis. Am J Surg 192: 311-6.

29. Lai HW, Loong CC, Chiu JH, Chau GY, Wu CW (2006) Interval appendectomy after conservative treatment of an appendiceal mass. World J Surg 30: $352-7$. 
30. Mosegaard A, Nielsen OS (1979) Interval appendectomy. A retrospective study. Acta Chir Scand. 145: 109-11.

31. Roggo A, Wood WC, Ottinger LW (1993) Carcinoid tumors of the appendix. Ann Surg 217: 385-90.

32. Lai HW, Loong CC, Tai LC, Wu CW, Lui WY (2006) Incidence and odds ratio of appendicitis as first manifestation of colon cancer: a retrospective analysis of 1873 patients. J Gastroenterol Hepatol 21: 1693-6.Ocre, ublisse, temporunte tabusque adeperiacta, que con din hac in se te, sum ommoero etiere, fursus estum

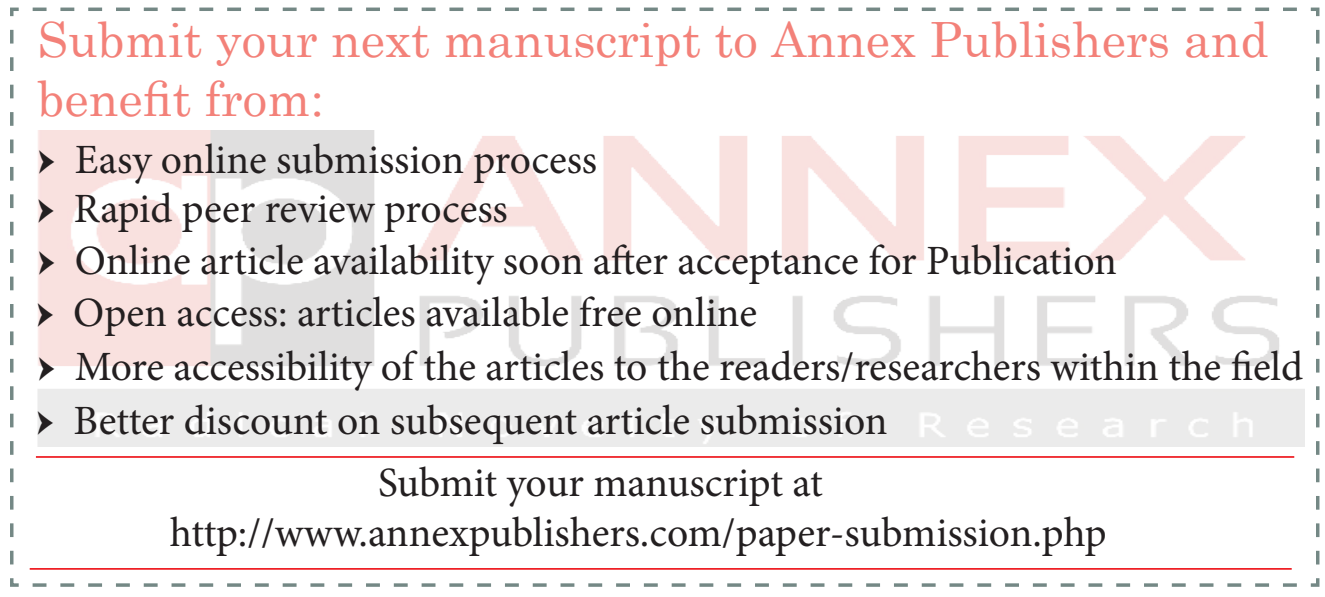

